\title{
Fe de errata/Errata
}

Rev Otorrinolaringol Cir Cabeza Cuello 2018; 78(3): 305-308. Tumor triquilemal proliferante: Reporte de un caso y revisión de la literatura.

[Trichilemmal proliferating tumor: Case report and literature review]

Eduardo Sáez C, Luis Cabezas C, Humberto Vallejos A, Cristian Bachelet R.

En la página 307 del citado artículo de Sáez y cols. de la versión impresa de Rev Otorrinolaringol Cir Cabeza Cuello (ISSN 0716-4084) no aparecen las figuras correctas del artículo.

Erratum in: Rev Otorrinolaringol Cir Cabeza Cuello 2018; 78(4): 465.

Figura 1. Lesión exofítica con ulceraciones en su superficie.
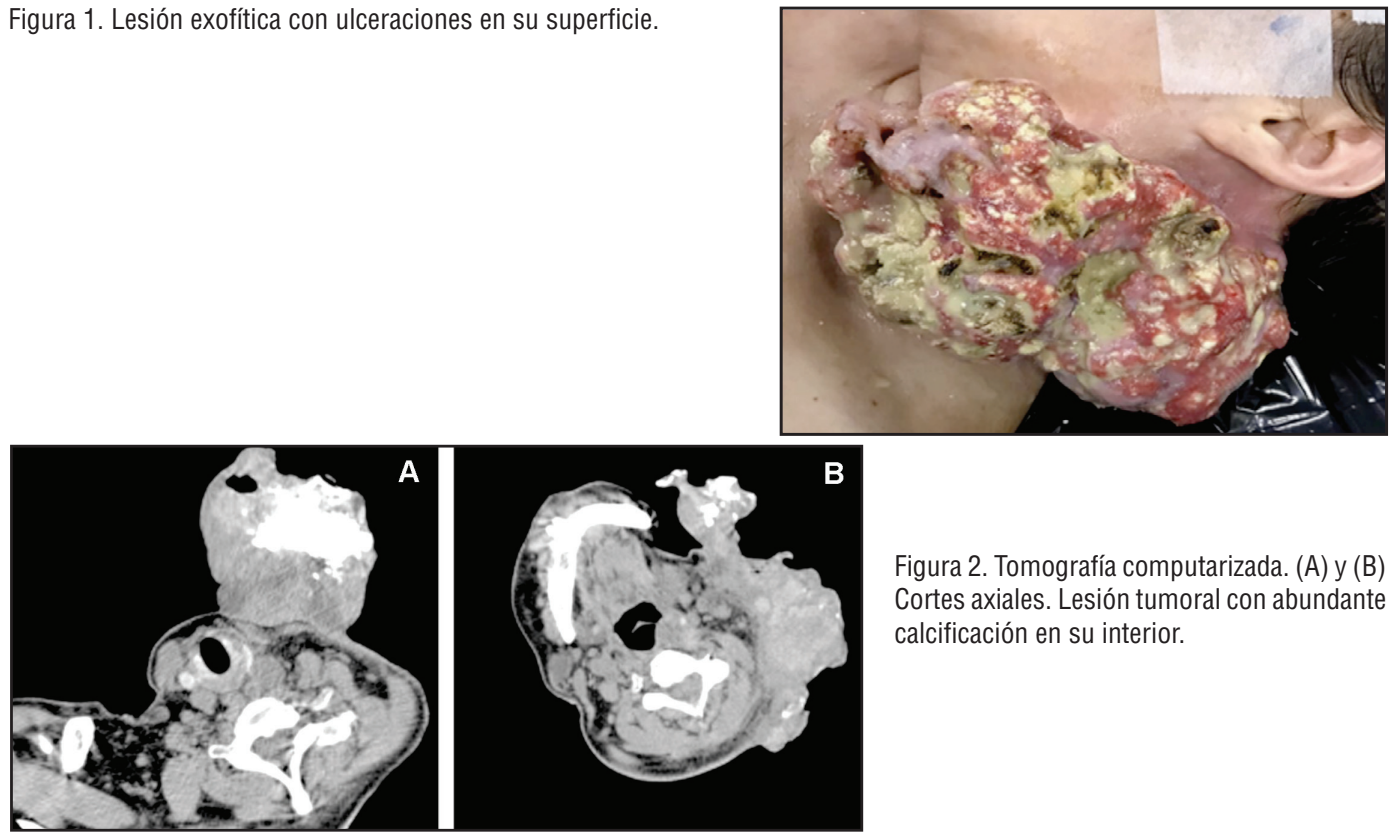

Figura 2. Tomografía computarizada. (A) y (B) Cortes axiales. Lesión tumoral con abundante calcificación en su interior.

Figura 3. Pieza operatoria. (A) Cara externa. (B) Cara interna.
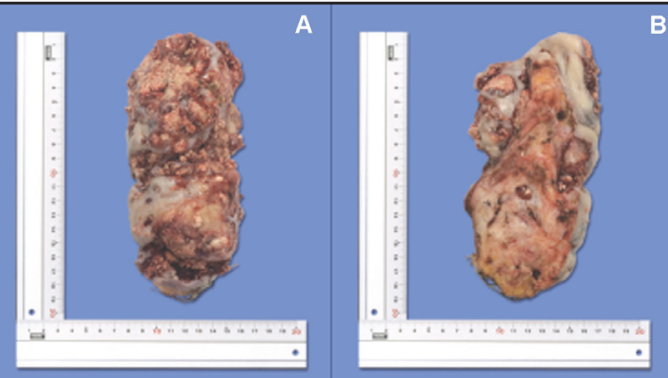

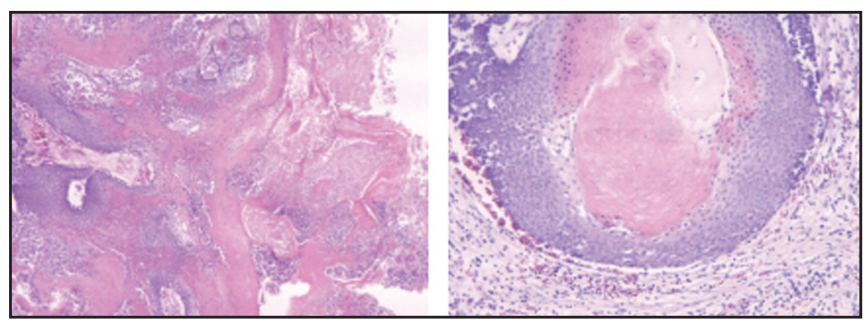

Figura 4. A la izquierda: (4X) masas de queratina en la superficie de la lesión con exudado inflamatorio. A la derecha (10X): se observa epitelio escamoso de tipo basaloide con abrupta queratinización central sin capa de células granulosas. 